\title{
Modelling and Simulation of Multi-Input Single-Output DC Power Supply Using Single Phase Matrix Converter (SPMC)
}

\author{
Mohd Shukri Mohd Ghazali, Muhammad Zulsyahmie Mohd Zaki, Rahimi Baharom, Nur Hidayah \\ Abdullah and Muhammad Shawwal Mohamad Rawi
}

\begin{abstract}
The multi-input converter is a power electronics device that has been used in various applications such as generating power by converting renewable energy, hybrid electric vehicle, and electronic equipment. This paper proposes a new circuit topology of Multi-Input Single-Output (MISO) DC power supply using Single-Phase Matrix Converter (SPMC). Compared to the typical circuit that uses at least two different circuits, the use of the proposed circuit topology only employed a single circuit to perform both rectifier and DC chopper operations. Two types of sources; AC and DC are connected to the input of the SPMC circuit. The SPMC switches will operate according to the integrated switching algorithms for $\mathrm{AC}$ to $\mathrm{DC}$ and DC to DC operations that are set by the controllers. The proposed circuit topology features the reduction of the number of components in the converter circuit, power losses, and circuit complexity, thus, improving the power density of the power supply system. A computer simulation of the proposed circuit has been designed and modeled using MATLAB/Simulink. The selected results are presented to verify the proposed system.
\end{abstract}

Index Terms - AC-DC operation, DC-DC operation, MultiInput Converter, Single-Phase Matrix Converter (SPMC).

\section{INTRODUCTION}

$\mathrm{T}$ HE power electronic converters are essential since the technology that linked AC and DC conversion has been designed with several control methods. The function of the power electronic converters is to control and modify the form of the electrical power that is transferred from the source to the load. Besides, it can also be operated in various applications such as the generation of power by converting renewable energy, hybrid electric vehicle, and electronic equipment $[1][2][3]$.

This manuscript is submitted on $21^{\text {st }}$ January 2021 and accepted on $28^{\text {th }}$ July 2021. This work was supported by the Reseach Management Centre (RMC) Universiti Teknologi MARA under Grant No: 600-RMC/YTR/5/3 (003/2020). Mohd Shukri Mohd Ghazali, Rahimi Baharom, Muhammad Shawwal Mohamad Rawi and Nur Hidayah Abdullah are with School of Electrical Engineering, College of Engineering, Universiti Teknologi MARA, 40450 Shah Alam, Selangor, Malaysia.

1985-5389/C 2021 The Authors. Published by UiTM Press. This is an open access article under the CC BY-NC-ND license (http://creativecommons.org /licenses/by-nc-nd/4.0/).
The multi-input converter is being developed to have the capability of converting the combination of energy and controlling the output appearing in the load. Most of the multiinput converter design system is following the concept of operation on boost converter [4][5][6]. The common structure of the multi-input converter usually had to parallel the multiple numbers of the converter circuits. The downside of this topology is the fact that the power can be supplied from only one source at once [7]. The magnetic coupling which uses a transformer can overcome the problem. However, the converter circuit needs to be multiple, which resulting in breaking the system, for instance, the system becomes bulky, reduces power density yet too complex to control.

Matrix converter is a device that can perform the conversion operation of $\mathrm{AC}$ and $\mathrm{DC}$ input using a single stage control circuit [8]. In 1980, Venturini and Alesina have developed the

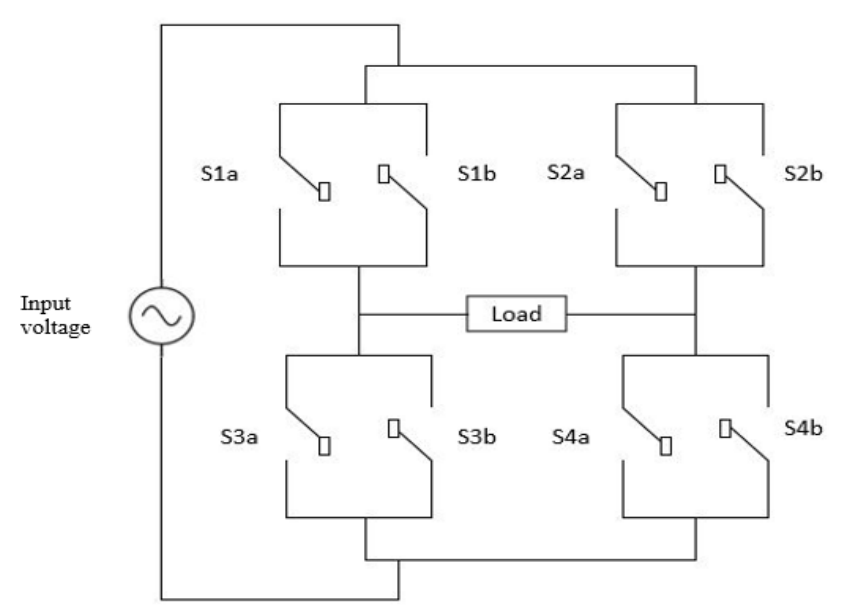

Fig. 1. SPMC circuit configuration.

Matrix converter which is able in regenerating the power back to the utility and controllable input current displacement factor [9][10]. The Single-Phase Matrix Converter (SPMC) was first realized by Zuckerberger [11]. By using the SPMC circuit, the components used in traditional rectifier-inverter based systems can be reduced since it has the capability to provide 
"all silicon" solution for AC-AC conversion[12]. Fig. 1 shows the SPMC circuit configuration.

There are many studies conducted to investigate the application of the SPMC topology for the rectifier [13], DC chopper [14], and inverter [15] operations. However, there is none of them that shows AC and DC can perform multi-input by using a single circuit SPMC. Therefore, this paper proposed a new circuit topology to convert two different sources of $\mathrm{AC}$ and DC by using SPMC to perform a multi-input DC power supply. The proposed system can reduce the size of the converter circuit with low power loss resulting in high power density. A computer simulation model has been developed and selected results have been presented to explore and validate the proposed technique using the MATLAB/Simulink (MLS).

\section{Multi InPUT CONVERTER USING SPMC}

The multi-input, AC, and DC forms will be converted by using the SPMC circuit topology. The switches of the converter are set and arranged for both rectifier and DC chopper conversion systems.

\section{A. Input AC Voltage}

The rectifier operation using SPMC can be presented according to the supply voltage in the positive and negative cycle operations. For the positive half-cycle operation as shown in Fig. 2, the current flows from AC source voltage to the load whenever a pair of switches S1a and S4a are turned ON. Fig. 3

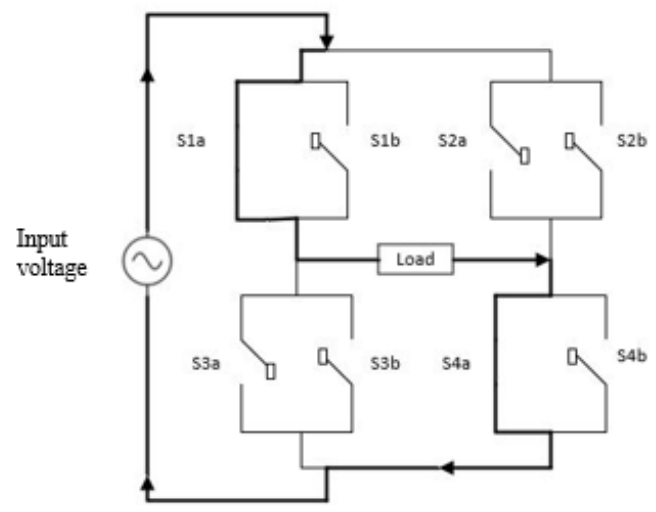

Fig. 2. Positive cycle operation.

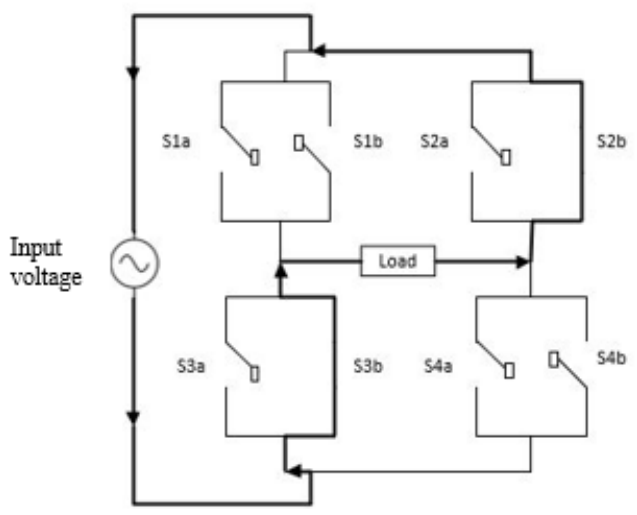

Fig. 3. Negative cycle operation. shows the operation in the negative half-cycle by turning $\mathrm{ON} \mathrm{a}$ pair of switches S2b and S3b [16].

In the SPMC circuit, the freewheeling diode in the conventional converter is not in need since it can be operated by controlling the respected switches [17][18] to dissipate the stored energy in the inductive load. On the other hand, SPMC switching needs to arrange properly to fade the residue energy to prevent damaging the converter [19] due to the current and voltage spikes as shown in Table I.

TABLE I

SWITCHING ARRANGEMENT FOR RECTIFIER OPERATION

\begin{tabular}{ccc}
\hline \hline State & Control Switch (PWM) & Commutation Switch "ON" \\
\hline 1 & S1a & S4a \& S3b \\
2 & S3b & S2b \& S1a \\
\hline \hline
\end{tabular}

\section{B. Input DC Voltage}

The DC to DC converter is known as a chopper circuit that is used to increase and decrease the DC power, which is similar to the transformers of the $\mathrm{AC}$ circuit. This converter can perform the process of converting a fixed DC voltage into variable $\mathrm{DC}$ voltage [20][21]. By using a DC chopper, it is possible to change the DC power supply to the devices according to the desired values. This is the simplest power electronic circuit that has the capability to buck or step down the DC voltage source [22].

DC chopper operation using SPMC topology requires different bidirectional switching arrangements to perform the TABLE II

ARRANGEMENT OF SWITCHING FOR DC-DC MATRIX CONVERTER WITH SAFECOMMUTATION STRATEGY

\begin{tabular}{ccccc}
\hline & Quadrant 1 & Quadrant 2 & Quadrant 3 & Quadrant 4 \\
\hline Switch 1a & ON & OFF & OFF & OFF \\
Switch 1b & OFF & ON & ON & OFF \\
Switch 2a & OFF & OFF & ON & OFF \\
Switch 2b & ON & OFF & OFF & ON \\
Switch 3a & OFF & PWM & PWM & OFF \\
Switch 3b & OFF & OFF & OFF & ON \\
Switch 4a & PWM & OFF & OFF & PWM \\
Switch 4b & OFF & ON & OFF & OFF \\
\hline \hline
\end{tabular}

four-quadrant operations [23][24]. The proposed switching sequences are as tabulated in Table II.

\section{1) First quadrant (Q1)}

The current flow for the forward motoring operation for Quadrant 1 is shown in Fig. 4. The load current flow from supply to the load is positive. By turning ON switches S1a and S4a which act as power switches for the converter operation, the current from the positive source will flow through the load before it flows back to the negative input supply to achieve the forward motoring operation [25]. 


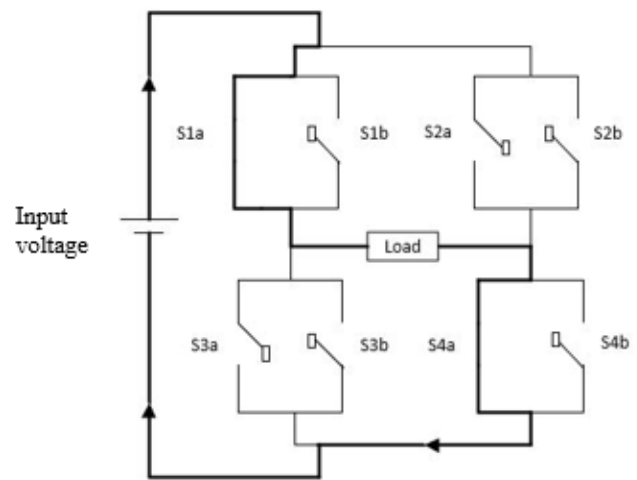

Fig. 4. Current flow for Q1.

\section{2) Second quadrant (Q2)}

As shown in Fig. 5, the operation for Quadrant 2 is forward braking mode. In this mode of operation, the voltage induced from the inductive load will become the main supply of the converter circuit, whilst the main DC source

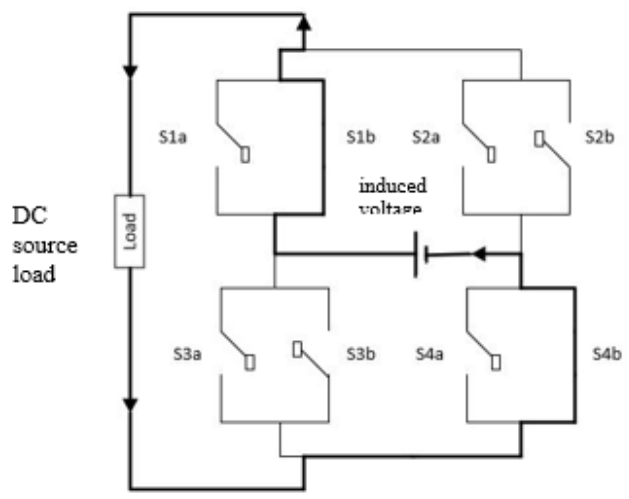

Fig. 5. Current flow for Q2.

will be the load. By turning ON switches S1b and S4b, it permits the current flows to achieve positive voltage with a negative current at the inductive load terminal.

\section{3) Third quadrant (Q3)}

The current flow for the reverse motoring operation in Quadrant 3 can be seen in Fig. 6. The load voltage and

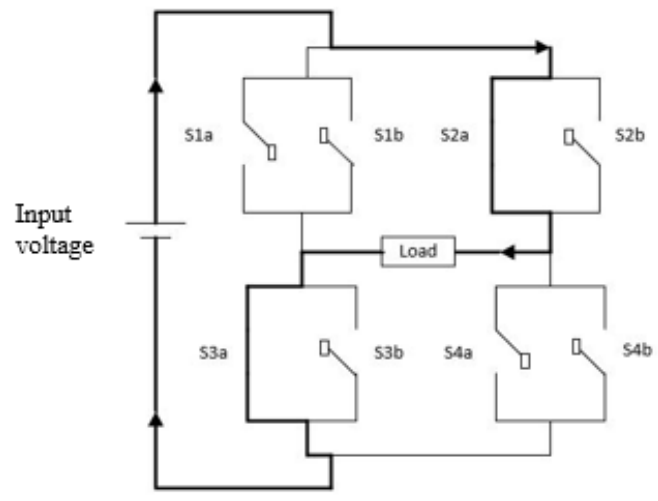

Fig. 6. Current flow for Q3.

current are negative since the current from the positive input supply will flow through the load before it flows back to the negative input source by turning ON switches S2a and S3a.

\section{4) Fourth quadrant (Q4)}

As illustrated in Fig. 7, the current flow for the reverse braking operation in Quadrant 4 is shown. The load voltage is negative, but the load current is positive because the current from the

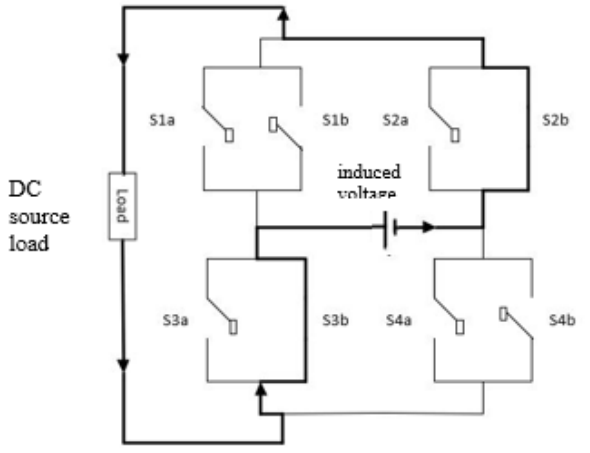

Fig. 7. Current flow for $\mathrm{Q} 4$.

back EMF (due to the inductive load) will flow to the load terminal and flow back to the negative input of back EMF by turning $\mathrm{ON}$ switches $\mathrm{S} 2 \mathrm{~b}$ and $\mathrm{S} 3 \mathrm{~b}$.

\section{METHODOLOGY}

The SPMC circuit is developed to operate for both rectifier and DC chopper operations. The operation of the multi-input converter has been visualized in the flowchart as shown in Fig. 8. The $100 \mathrm{VAC}$ supply, with $50 \mathrm{~Hz}$ frequency, and $30 \mathrm{VDC}$ are used to supply the proposed system. The power range is below 100 Watt.

The operation of the proposed system begins from the selection of the input voltage supply either in AC or DC forms by using the switch selector. Then, the controllers will be triggered to control the SPMC to operate as a rectifier or DC chopper operations. Finally, the desired output voltage and current waveforms can be obtained to control the four-quadrant operations of DC machines.

The block diagram of the proposed system is as shown in Fig. 9. The main parts for the proposed system are Multi-Input which is either AC input or DC input that is connected to a single SPMC circuit. Then the SPMC circuit will be controlled with PWM signal and suitable switching algorithms as mentioned in Table I and Table II to convert any form of inputs to the $\mathrm{DC}$ form. 


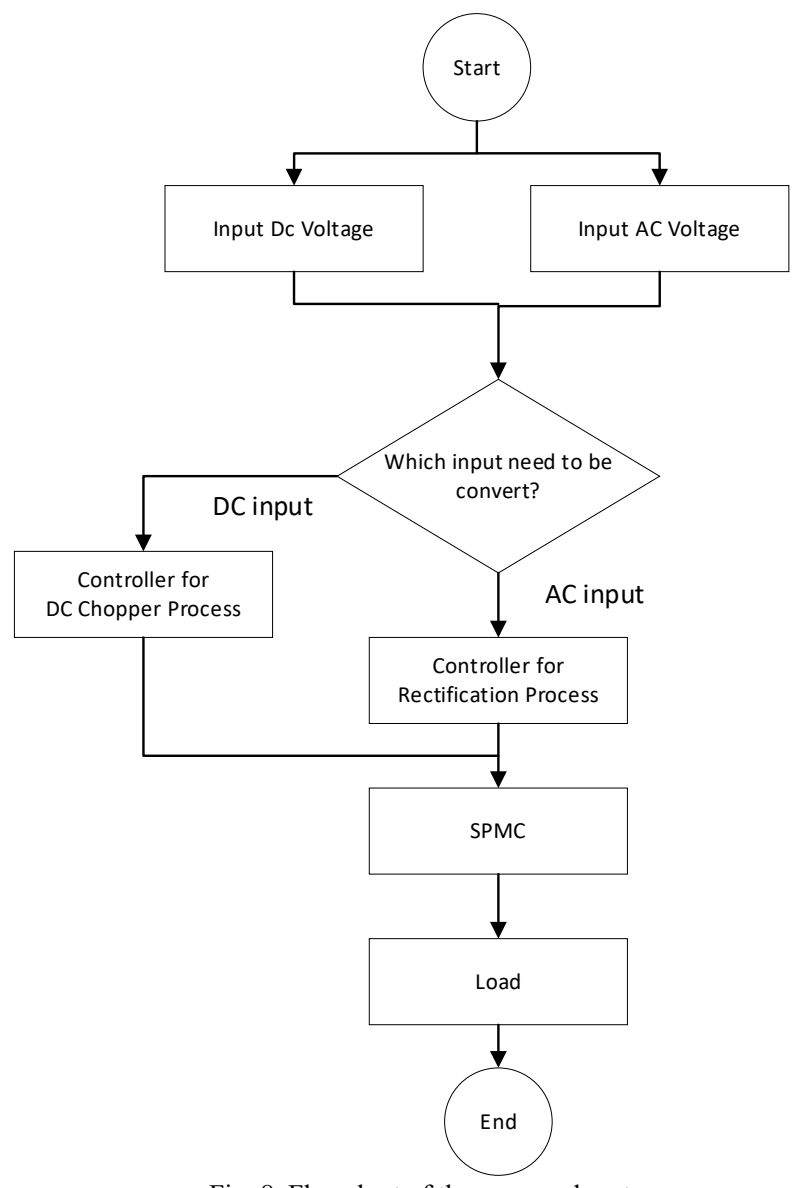

Fig. 8. Flowchart of the proposed system.

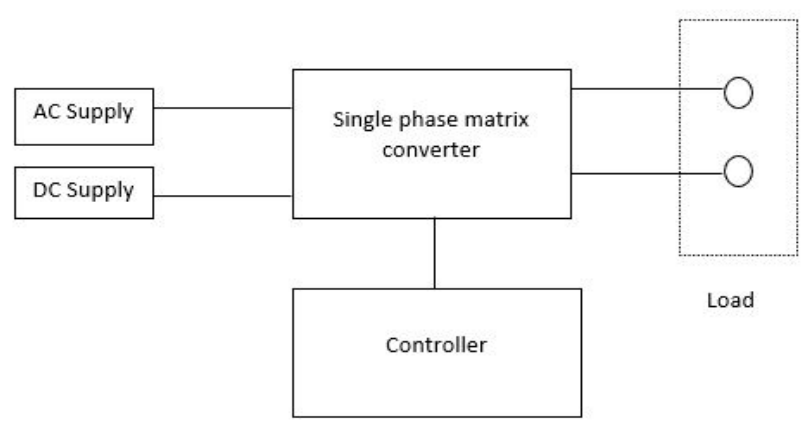

Fig. 9. Block diagram of Multi-Input Single Output.

\section{COMPuter Simulation Model}

The computer simulation model of the proposed circuit has been carried out using MATLAB/Simulink. The use of the computer simulation model can help to investigate the circuit behavior and study the function of the controller for the two inputs into a single DC output converter based on SPMC circuit topology. The parameters used for the computer simulation model are listed in Table III.
TABLE III

PARAMETER FOR THE COMPUTER SiMUlation MODEL

\begin{tabular}{lc} 
Parameters & Value \\
\hline DC voltage & $30 \mathrm{~V}$ \\
AC voltage & $100 \mathrm{~V}$ \\
Resistance & $150 \Omega$ \\
Capacitance & $1000 \mu \mathrm{F}$
\end{tabular}

\section{A. SPMC Topology Model}

The SPMC circuit is capable of conducting current in both directions, and this circuit is developed by the four bidirectional switches; S1, S2, S3, and S4 as shown in Fig. 10. Each bidirectional switch used an IGBT switch with diode pairs in a common emitter configuration as shown in Fig. 11.

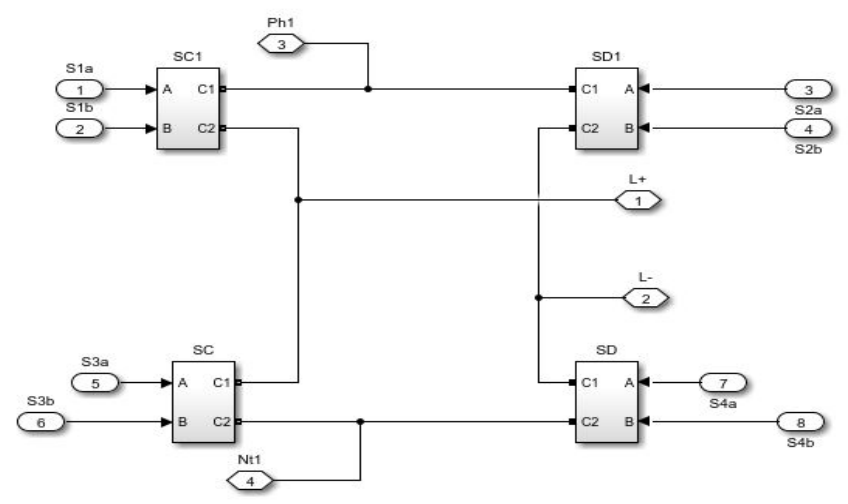

Fig. 10. Single-Phase Matrix Converter circuit

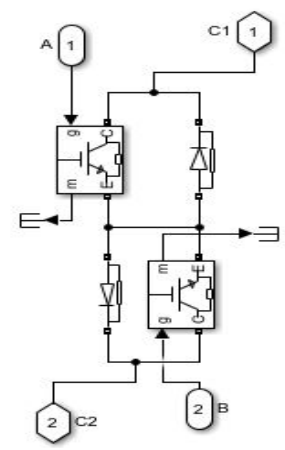

Fig. 11. Bi-directional switches

\section{B. MISO Proposed Model}

The proposed circuit model is as shown in Fig. 12. The circuit consists of two controllers both for rectifier and DC chopper operations, and the SPMC circuit. The model is simulated with the subsystem to simplify the circuit from the larger model into the smaller model. The resistive load is being represented by the connection of the resistor to the output of the SPMC. 


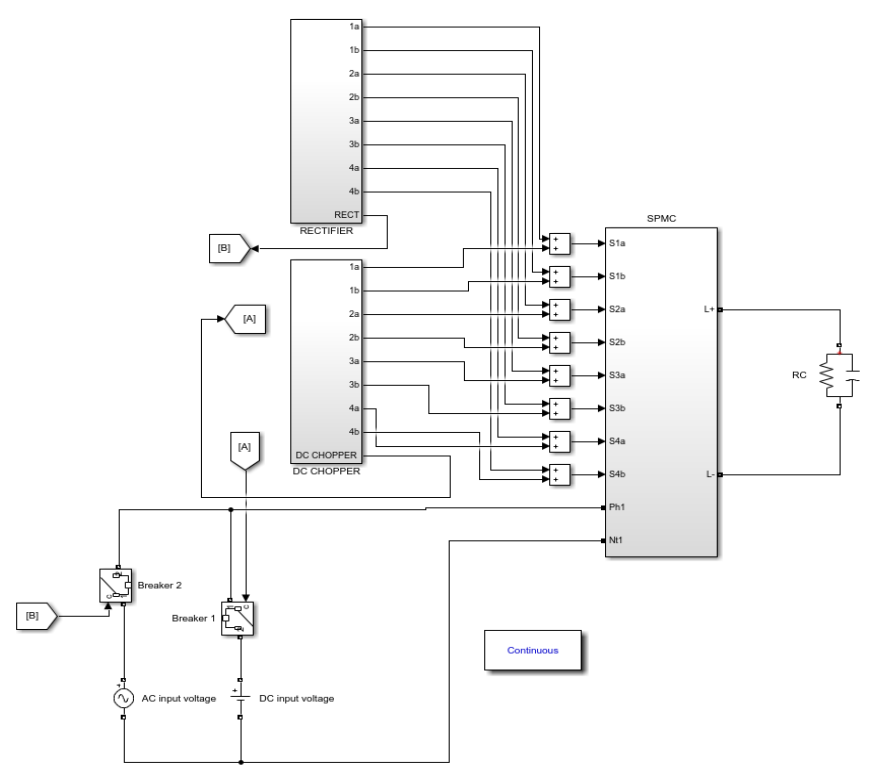

Fig. 12. The proposed circuit in MLS.

\section{DC Chopper Controller Model}

Fig. 13 shows the circuit model of the controller for the DC chopper operation for Quadrant 1 where S4a was connected to the PWM signal and S2b and S2a were always turned ON. Quadrant 2, 3, and 4 are the same as Fig. 13 except their switching algorithms are different based on Table II.

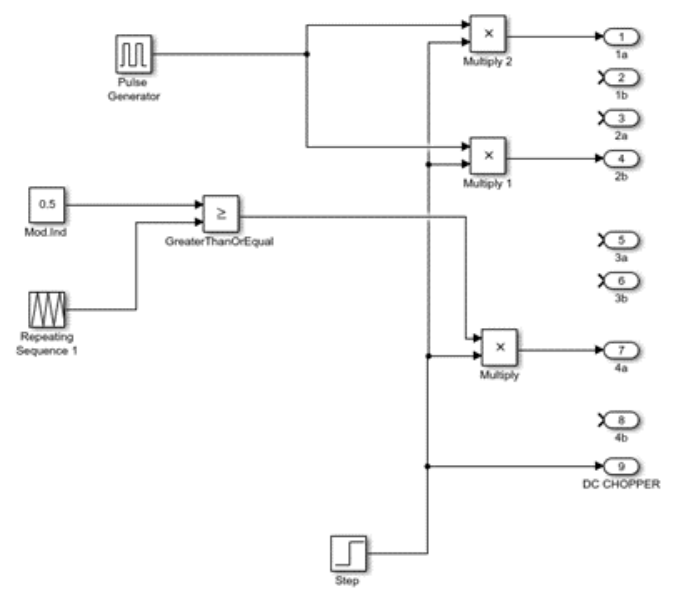

Fig. 13. Controller circuit for DC chopper operation for Quadrant 1

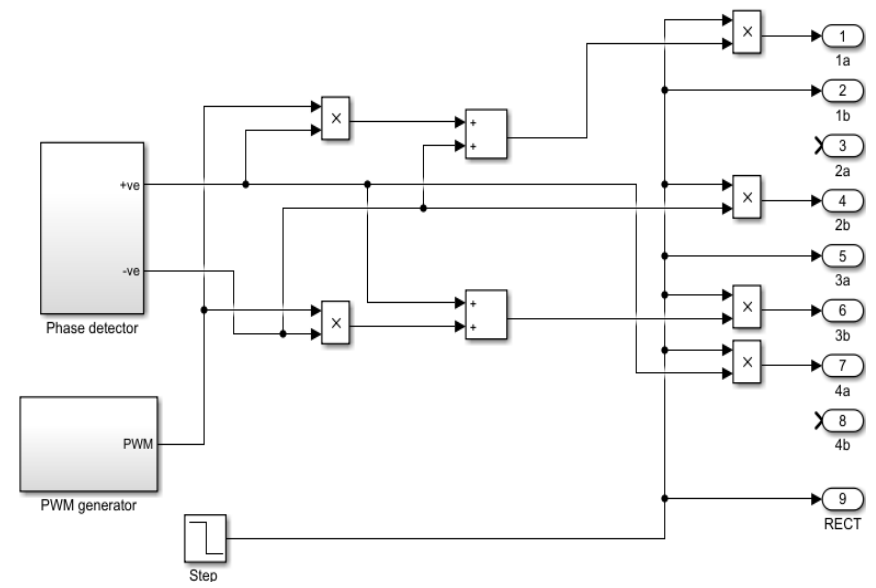

Fig. 14. Controller circuit for rectifier operation.
Fig. 14 shows the circuit model of the controller for the rectifier operation that has been developed based on Table I.

\section{RESULT AND DISCUSSION}

Fig. 15 and 16 show the voltage waveforms at the supply and load terminal for control rectifier operation. The figures show that voltage waveforms have been rectified into DC forms. Therefore, the SPMC has been successfully performing the rectifier operation which is to convert AC to DC form. Through a proper safe-commutation technique, the spikes induced due to the inductive load were successfully eliminated, thus, verify the workability and the effectiveness of the proposed safecommutation strategy. The usage of an RC filter at the DC side of the rectifier to generate smooth DC output, were successfully to minimize the ripples.

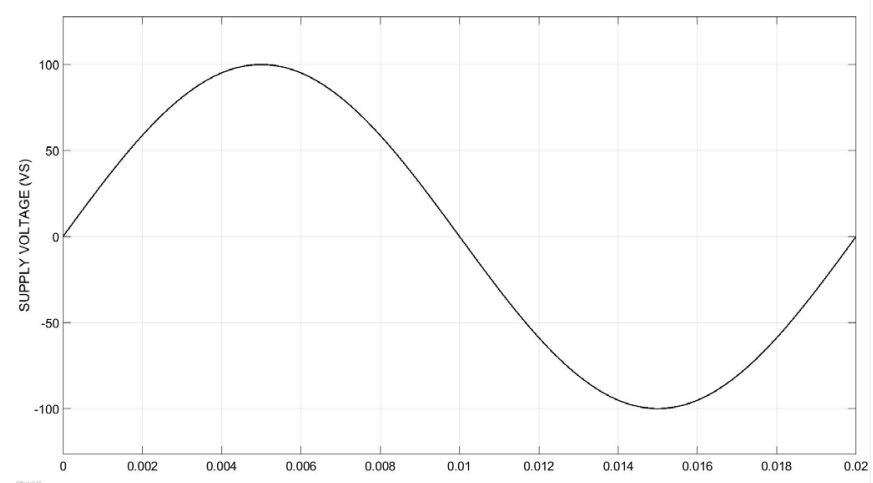

Fig. 15. The supply voltage waveform for rectifier operation

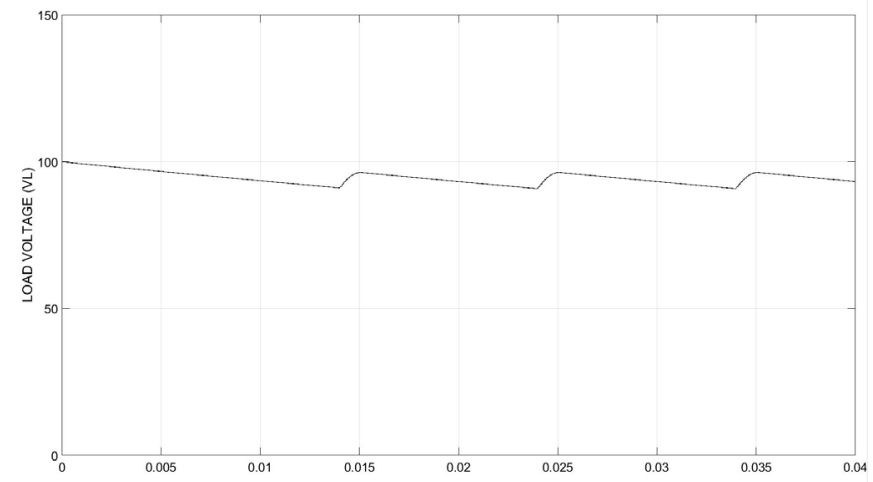

Fig. 16. The load voltage waveform for rectifier operation

The results for the DC chopper operation are presented in Fig. 17 to 24. For Quadrant 1 operation, the positive load current and voltage are shown in Fig. 17 and 18. This means that the system is operating in the forward motoring mode. Therefore, the SPMC has been successfully performing the DC chopper operation to fulfill the Quadrant 1 characteristic as mentioned in the previous section. 


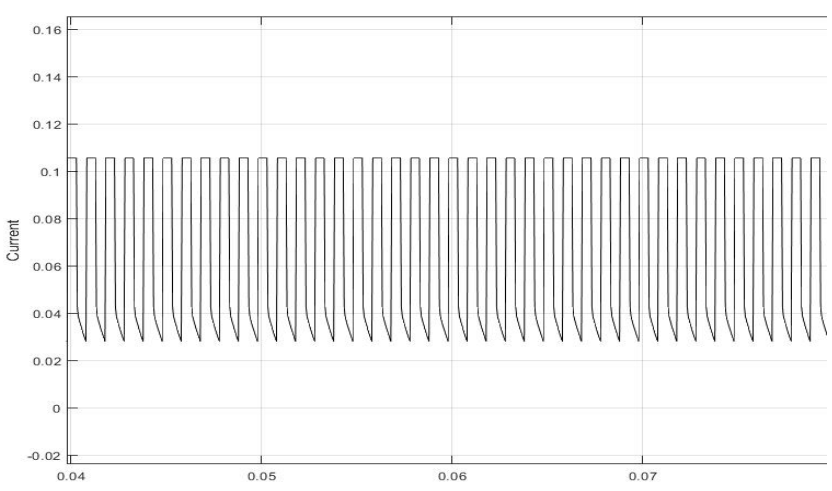

Fig. 17. The output current waveform for Quadrant 1 operation

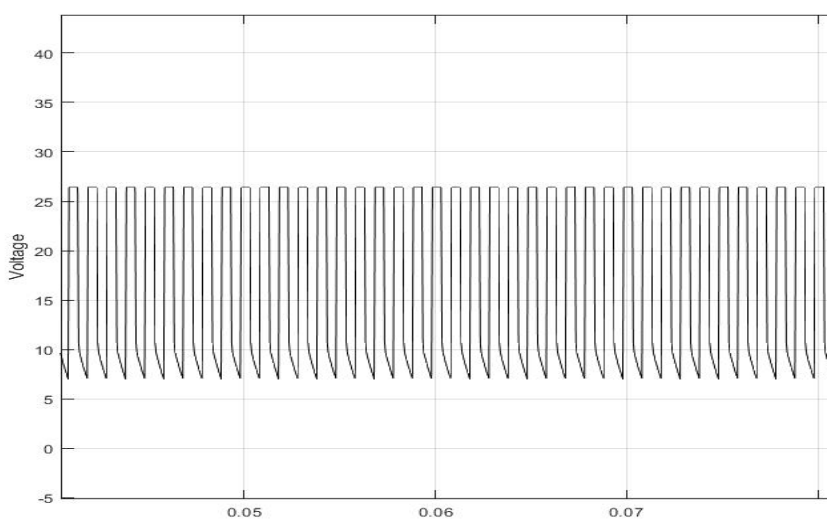

Fig. 18. The output voltage waveform for Quadrant 1 operation

The results of the DC chopper for the Quadrant 2 operation have been successfully implemented as shown in Fig. 19 and 20 , where the load voltage is in the positive, while the load current is in the negative polarities. Therefore, as stated in the previous section, the SPMC successfully performed the DC Chopper operation to meet the Quadrant 2 characteristic.

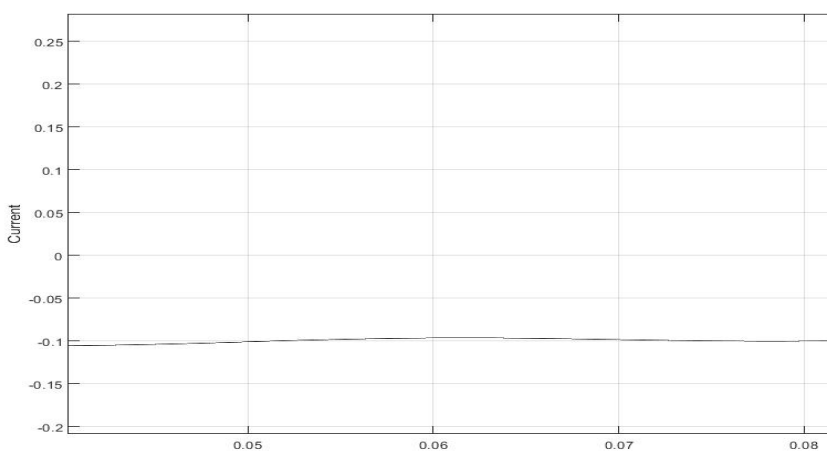

Fig. 19. The output current waveform for Quadrant 2 operation

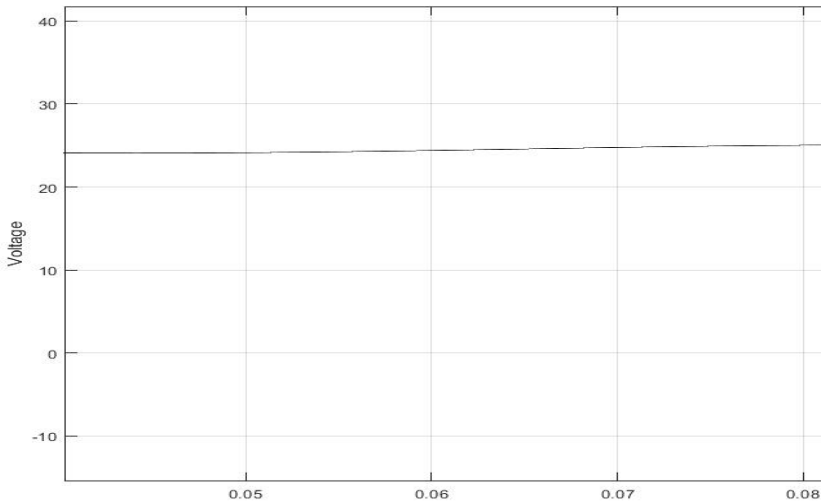

Fig. 20. The output voltage waveform for Quadrant 2 operation

Fig. 21 and 22 show the output voltage and current waveforms are both in the negative polarity, thus, verify that the SPMC has successfully conducted the DC Chopper operation effectively for Quadrant 3 operation.

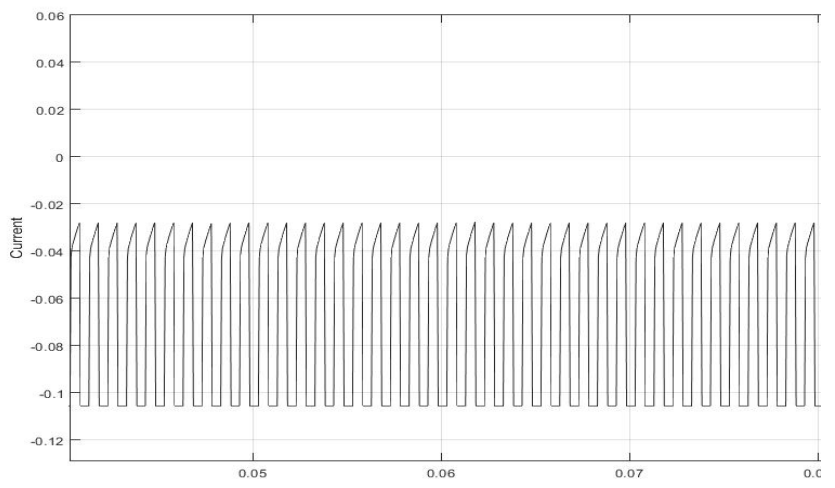

Fig. 21. The output current waveform for Quadrant 3 operation

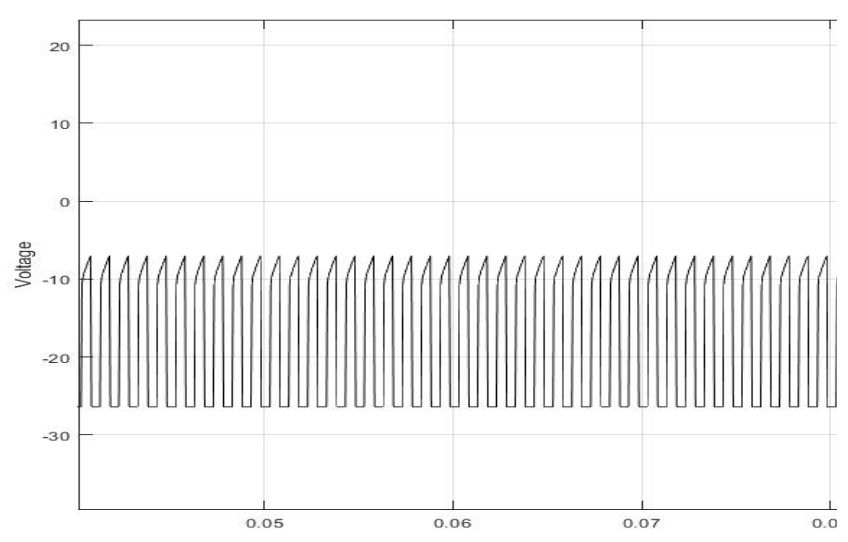

Fig. 22. The output voltage waveform for Quadrant 3 operation

As shown in Fig. 23, the output voltage waveform is negative, whilst the output current is in the positive polarity as shown in Fig. 24. These characteristics verify that the SPMC has successfully performed the DC chopper operation for the Quadrant 4 operation. 


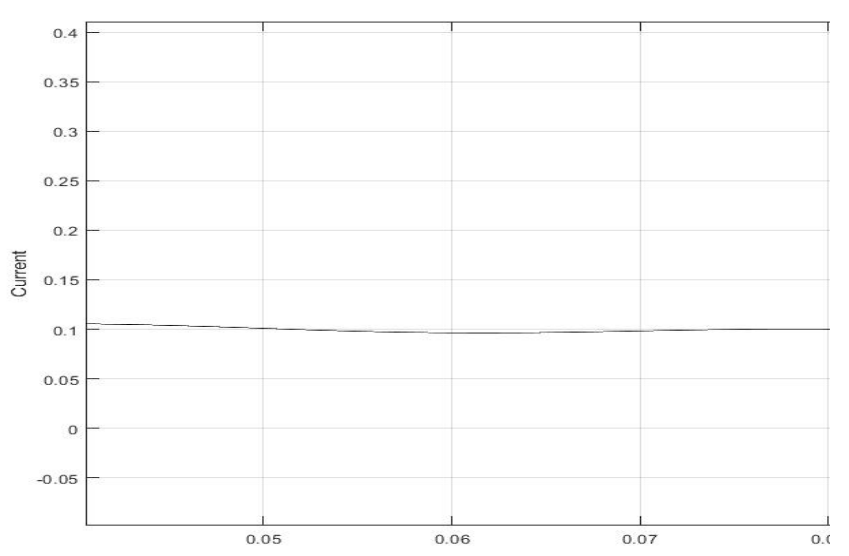

Fig. 23. The output current waveform for Quadrant 4 operation

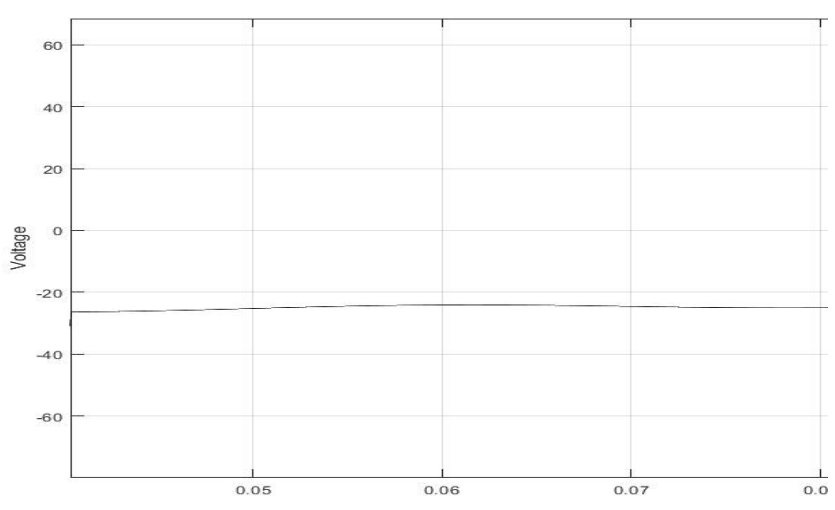

Fig. 24. The output voltage waveform for Quadrant 4 operation

Based on the results from the computer simulation model, it shows that the SPMC can be used to operate as a rectifier [13] and DC chopper [14]. Therefore, the SPMC topology is suitable to implement the Multi-Input Single-Output (MISO) converter that allows users to have input from either AC or DC sources and thus utilize them in DC types of loads. The use of a single circuit of the SPMC topology to perform a MISO converter instead of at least two separate circuits to perform the rectifier, and DC chopper will lead to low electronic component usage resulting in low power losses and increase the power density of the power converter. This is in line with the current trend in power electronics converter to increase the converter power density, especially for IT applications, where rapid advancements in integrated circuit technology have resulted in more compact systems with higher power consumption [26].

\section{CONCLUSION}

In this paper, the proposed Multi-Input Single Output converter has been presented. The proposed system has been verified through the output voltage and current profiles that show a good agreement with the theoretical studies. This proved that using a single circuit topology of the converter, it can perform two operations of power conversion (rectifier and DC chopper) with different voltage sources (AC or DC). Therefore, the proposed system can increase the power density, thus, decrease the power losses as well as the cost of the power converter system. The proposed system can be improved for better system enhancement by developing the multi-input and multi-output using the SPMC. Consequently, the system can select the input that needs to be converted into variable output.

For future recommendation, the design for the rectifier converter to include the LC filter at the DC side of the rectifier to generate smooth DC output and the validation for this circuit can be done through the experimental test-rig. As a suggestion to increase the power density of the power converter, this MISO converter can be developed with a single SPMC circuit and a single microcontroller to reduce the electronic component usage, size, cost, volume, and power loss of the converter.the importance of the work or suggest applications and extensions.

\section{ACKNOWLEDGMENT}

Financial support from Research Management Centre (RMC), Universiti Teknologi MARA Shah Alam, Malaysia, research grant RMI File No: 600-RMC/YTR/5/3 (003/2020) is gratefully acknowledged.

\section{REFERENCES}

[1] G. Ozkan, B. Papari, P. H. Hoang, N. Deb, and C. S. Edrington, "An Active Thermal Control Method for AC-DC Power Converter with Sequence-based Control Approach," 2019 IEEE Electr. Sh. Technol. Symp. ESTS 2019, pp. 263-267, 2019.

[2] M. Lepanov and Y. Rozanov, "Multifunctional regulator based on SMES and power electronic converter for increase of power quality and power supply reliability," 4th Int. Conf. Power Eng. Energy Electr. Drives, pp. 1387-1391, 2013.

[3] B. Shanmugam, R. Deekshit, and C. R. Prahallad, "Design and implementation of power electronic converters in wind turbine system," 2017 Int. Conf. Smart Grids, Power Adv. Control Eng. Icsp. 2017, pp. 106-113, 2018.

[4] A. Kwasinski, "Identification of feasible topologies for multipleinput DC-DC converters," IEEE Trans. Power Electron., vol. 24, no. 3, pp. 856-861, 2009.

[5] S. Khosrogorji, H. Torkaman, and F. Karimi, "A short review on multi-input DC/DC converters topologies," 6th Annu. Int. Power Electron. Drive Syst. Technol. Conf. PEDSTC 2015, pp. 650-654, 2015.

[6] J. Jose, B. Sreenath, and M. Das B, "Multi-Input Dc - Dc / Ac Boost Converter," Int. J. Adv. Comput. Electron. Technol., vol. 2, no. 3, 2015.

[7] Z. Rehman, I. Al-Bahadly, and S. Mukhopadhyay, "Multiinput DCDC converters in renewable energy applications - An overview," Renew. Sustain. Energy Rev., vol. 41, pp. 521-539, 2015.

[8] J. Zhang, L. Li, and D. G. Dorrell, "Control and Applications of Direct Matrix Converters : A Review," Chinese J. Electr. Eng., vol. 4, no. 2, pp. 18-27, 2018.

[9] A. Alesina and M. Venturini, "Solid-State Power Conversion: A Fourier Analysis Approach to Generalized T ransformer Synthesis," IEEE Trans. Circuits Syst., vol. 28, 1981.

[10] A. Alesina and M. G. B. Venturini, "Analysis and design of optimumamplitude nine-switch direct AC-AC converters," IEEE Trans. Power Electron., vol. 4, pp. 101-112, 1989.

[11] A. Zuckerberger, D. Weinstock, and A. Alexand, "Single-phase matrix converter," IEE Proc. Electr. Power App, vol. 144, no. 4, pp. 235-240, 1997.

[12] M. N. S.Z., A. R. N.F., and H. M.K., "Single Phase Matrix Converter Operating as a Four Quadrant DC Chopper controlled using Xilinx FPGA,” Int. J. Electr. Electron. Syst. Res., vol. 4, pp. 19-30, 2011.

[13] R. Baharom, N. Hashim, and M. K. Hamzah, "Implementation of controlled rectifier with power factor correction using single-phase matrix converter," Proc. Int. Conf. Power Electron. Drive Syst., pp. 1020-1025, 2009.

[14] F. Kadir, S. Z. Mohammad Noor, F. A.H., and K. S. Muhammad, "Modelling and Simulation of a DC-DC boost converter Using Single Phase Matrix Converter Topology," Int. J. Power Electron. Drive Syst., vol. 11, no. 2, pp. 774-784, 2020. 
[15] V. Satish, S. K. Konathala, and A. U. R. Kiran, "Design and Implementation of Single Phase Matrix Converter for Cycloconverter Operation,” Int. J. Eng. Res. Technol., vol. 3, no. 1, pp. 922-927, 2014.

[16] R. Baharom, N. R. Hamzah, and M. K. Hamzah, "A new safecommutation technique for AC-DC converter operation using singlephase matrix converter," PECon 2012 - 2012 IEEE Int. Conf. Power Energy, no. December 2012, pp. 298-302, 2012.

[17] R. Baharom, A. S. A. Hasim, H. M. K., and M. F. Omar, "A new single-phase controlled rectifier using single-phase matrix converter," 2006 IEEE Int. Power Energy Conf., pp. 453-458, 2006.

[18] R. Baharom, N. R. Hamzah, and M. K. Hamzah, "Advanced singlephase AC-DC converter using single-phase matrix converter topology," 2010 IEEE Int. Energy Conf., pp. 108-113, 2010.

[19] P. S. Jose, N. C. Deepika, and S. N. Nisha, "Applications of single phase matrix converter," 2011 Int. Conf. Emerg. Trends Electr. Comput. Technol. ICETECT 2011, pp. 386-391, 2011, doi: 10.1109/ICETECT.2011.5760148.

[20] D. Ahirrao, B. Gaware, P. Kakade, P. Kharade, and P. S. Chawda, "Analysis Of Single Phase Matrix Converter," Int. J. Eng. Res. Appl., vol. 4, no. 3, pp. 856-861, 2014.

[21] S. Z. M. Noor, M. K. Hamzah, and A. F. Abidin, "Modelling and simulation of a DC chopper using single phase matrix converter topology," Proc. Int. Conf. Power Electron. Drive Syst., vol. 1, pp. 827-832, 2005.

[22] S. K, "Universal Matrix Converter for AC and DC Power Conversions," 2017 IEEE Int. Conf. Circuits Syst., pp. 392-397, 2017.

[23] E. V. S. Sneha and M. Sajin, "Design and Simulation of Single Phase Matrix Converter as a Universal Converter," Int. J. Eng. Res. Technol., vol. 2, no. 11, pp. 1471-1474, 2013.

[24] A. J. Forsyth and S. V. Mollov, "Modelling and control of DC-DC converters." pp. 229-236, 1998.

[25] R. Baharom and A. M. Awang, "Development of four quadrant operation of DC to DC converter using single phase matrix converter," Indones. J. Electr. Eng. Comput. Sci., vol. 16, no. 3, pp. 1249-1256, 2019.

[26] J. W. Kolar, U. Drofenik, J. Biela, M. L. Heldwein, H. Ertt*, T. Friedli and S. D. Round, "PWM Converter Power Density Barriers", 2007 Power Conversion Conference - Nagoya, Year: 2007. 